\title{
Biochanin A extirpates the epithelial-mesenchymal transition in a human lung cancer
}

\author{
YAN WANG ${ }^{1 *}$, JIAO-JIAO LI $^{2 *}$ and YU-MIN CHEN ${ }^{1}$ \\ ${ }^{1}$ Department of Cardiovascular and Thoracic Surgery; ${ }^{2}$ Intensive Care Unit, Renmin Hospital, \\ Hubei University of Medicine, Shiyan, Hubei 442000, P.R. China
}

Received May 2, 2016; Accepted March 31, 2017

DOI: $10.3892 /$ etm.2018.5731

\begin{abstract}
The natural iso-flavonoid, biochanin A, is categorized as a phytoestrogen and has been demonstrated to exhibit various pharmacological properties. However, no effects of biochanin A on lung cancer cell lines have been reported. Therefore, the present study aimed to demonstrate whether biochanin A has the ability to reduce lung cancer triggered pro-inflammatory effects from leukemic monocytes. We studied the release of cytokines, tumor necrosis factor (TNF)- $\alpha$ and interleukin (IL)-6, from the cocultured cells of A427:AML-193. In addition to this, epithelial-mesenchymal transition was also monitored. In the cocultured A427 and AML-193, AML-193 was stimulated by A427 cells assisting the release of TNF- $\alpha$ and IL- 6 cytokines, but the addition of A427 with biochanin A reduced A427-triggered generation of cytokines by AML-193. Moreover, this non-functional A427:AML-193 coculture reduced the metastasis effects of A427 cells, as determined by wound healing assays and migration/invasion assays. These results were further confirmed by a reduction in Snail and E-cadherin expression levels, which are indicators of the epithelial-mesenchymal transition. These findings suggest the therapeutic effect of biochanin A against lung cancer evoked inflammation and pro-inflammatory functions from monocytic cells.
\end{abstract}

\section{Introduction}

Cancer-associated mortality rates are the highest worldwide. It was found that the lethal rate among cancer patients remains large due to the insufficient capabilities of existing cancer therapies (1). Among the different cancer types, lung cancer

Correspondence to: Dr Yu-Min Chen, Department of Cardiovascular and Thoracic Surgery, Renmin Hospital, Hubei University of Medicine, 37 Chaoyang Road, Maojian, Shiyan, Hubei 442000, P.R. China

E-mail: chenyumin329@hotmail.com

*Contributed equally

Key words: biochanin A, epithelial-mesenchymal transition, A427 is considered as the largest contributor to cancer-associated mortality and exhibits a serious health issues (2). Furthermore, lung cancer is the second most diagnosed type of cancer and accounts for $30 \%$ of cancer-associated mortality rates (3). In Europe, frequency rates of lung cancer have reduced but the rate of survival remains below $20 \%$ (4). Statistics reported in United States during 2015 indicate that lung cancer and bronchus cancer are responsible for a mortality rate of $\sim 158,080$ individuals (5). Although there have been high-tech advancements, no convincing increase in 5-year survival rates has been observed for lung cancer during the past decade (5). This is due to a lack of sufficient knowledge of the biological functions that maintain lung carcinogenesis. Among all other types of cancers, the mortality rates are markedly higher for lung cancer and non-small cell lung cancer is the predominant lung cancer type. It is well-known that patients with metastasis have a lower survival period $(6,7)$ and hence, the aim of our treatment was to suppress metastasis.

Epithelial-mesenchymal transition (EMT) has been demonstrated to be an essential process not only during embryonic progression but also as a powerful mechanism for cancer growth. EMT refers to a process in which cells were subjected to the transition from an epithelial phenotype to a mesenchymal phenotype. Cells alter their morphology to have advanced motility. Furthermore, EMT has been demonstrated to have a crucial function in metastasis (8). EMT can be well distinguished by its high association between the gain and loss of mesenchymal-like markers and epithelial-like cell junction proteins, including $\mathrm{N}$-cadherin or vimentin and E-cadherin respectively (9). Transcriptional suppression in E-cadherin is activated via regulators of EMT, such as Snail and Slug; induction of cancer metastasis is mediated by the same process (10-12).

To date, usage of herbal compounds has increased along with the use of antibiotic drugs, particularly in Western countries. The purpose of using herbal medicines is to suppress side effects when combined with modern medicines or to afford interdependent pharmacological properties (13). Generally, it is believed that herbal medicines are secure for human intake since they are naturally occurring; however, numerous studies have revealed that different elements of these natural compounds can lead to severe modulations in pharmacological characteristics of co-governed drugs, thus altering their power and security (14-16). 
Phytoestrogens, commonly known as dietary isoflavones, occur extensively in the Leguminosae family. These secondary metabolite plants display protective effects against several diseases, including osteoporosis, cancers and heart-related diseases (17,18). Among them, Biochanin $\mathrm{A}$, which is an O-methylated isoflavone present in chickpea, red clover, alfalfa and cabbage, has been documented to have anti-tumor, anti-viral, and anti-inflammatory properties $(19,20)$. Inhibition of tumor necrosis factor (TNF)- $\alpha$ and interleukin (IL)-6 production in lipopolysaccharide-induced macrophages was observed with biochanin A treatment in a previous study (21). Previous reports of biochanin A have identified several biological characteristics, such as anti-proliferation, anti-oxidation, anticancer and hypoglycemic properties (22-26). Suppression of ovalbumin-mediated airway hyper-responsiveness was also noted with biochanin A supplementation (27).

In a previous study, biochanin A exhibited beneficial anti-oxidant activity in mice, which indicated its promise for treating Alzheimer's disease (20). Meanwhile, anti-apoptotic (28) and anti-fibrotic (29) properties of biochanin A have also been revealed. However, the anticancer effect of biochanin A on A427 lung cancer cell lines remains unclear. The aim of this study was to determine the anticancer properties of biochanin A on lung cancer cell lines and to illustrate the potential anticancer mechanism.

\section{Materials and methods}

Chemicals and reagents. Biochanin A, dimethyl sulfoxide (DMSO), 3-(4,5-dimethylthiazol-2-yl)-2,5-diphenyl tetrazolium bromide reagent for MTT assay, antibodies for $\beta$-actin (cat. no. A5441), E-Cadherin (cat. no. 07-697) and Snail (cat. no. SAB1306281), TNF- $\alpha$ (cat. no. T0813) and IL-6 (cat. no. MABF41) were acquired from Sigma-Aldrich (Merck KGaA, Darmstadt, Germany). Cell culture medium, including Dulbecco's modified Eagle medium (DMEM) and RPMI-1640 medium, and the other supplements required for cell culture methods, including fetal bovine serum, penicillin and streptomycin, were purchased from Thermo Fisher Scientific, Inc. (Waltham, MA, USA).

Cell culture and methods. Human lung adenocarcinoma cell line (A427) and human monocytic leukemia cell line (AML-193) were obtained from American Type Culture Collection (Manassas, VA, USA). A427 cell lines were cultured in DMEM, whereas AML-193 cells were cultured in RPMI medium. Both the media were supplemented with $10 \%$ fetal bovine serum, $100 \mathrm{U} / \mathrm{ml}$ penicillin and $100 \mathrm{mg} / \mathrm{ml}$ streptomycin under a humidified atmosphere at $37^{\circ} \mathrm{C}$ with $5 \%$ $\mathrm{CO}_{2}$. Biochanin A was dissolved using dimethyl sulfoxide to prepare a stock solution and was stored at $4^{\circ} \mathrm{C}$ for subsequent experiments.

MTT assay. The sub-lethal dosage of biochanin A on A427 cells was examined to assess cell viability using an MTT assay. In order to conduct this experiment, cells at a density of $3 \times 10^{3}$ cells/well were seeded into 96-well plates and incubated for $24 \mathrm{~h}$. Following culturing, various concentrations of biochanin $\mathrm{A}(5,20$ and $40 \mu \mathrm{M})$ were added by dissolving the compound in DMSO and incubating a further $24 \mathrm{~h}$. After this, the media were removed and $0.1 \mathrm{mg} / \mathrm{ml}$ MTT solution was added followed by 6 - $\mathrm{h}$ incubation in the dark. This was followed by the addition of DMSO of equal volume to solubilize the formazan crystals and their absorbance at $560 \mathrm{~nm}$ was recorded using a microplate reader (Sunrise; Tecan, Männedorf, Switzerland). Cells treated without biochanin A in DMSO acted as vehicle controls and the experiment was performed in triplicate.

Coculture method, biochanin A treatment and acquiring conditioned medium. A427 human lung cancer cell lines were subjected to coculture with human monocytic leukemic AML-193 cells. Ratios (1:1, 1:10, 1:15, 1:25 and 1:50) were chosen to illustrate the role of biochanin $\mathrm{A}$ in a potential pro-inflammation coculture method. In brief, A427 cells at a density of $3 \times 10^{3}$ cells/well were seeded into 96 -well plates and maintained overnight in DMEM supplemented with fetal bovine serum $(10 \%)$ in order to grow the cells. This was followed by the addition of various biochanin A sub-lethal concentrations $(5,20$ and $40 \mu \mathrm{M})$ and incubation for $24 \mathrm{~h}$. Following incubation, PBS solution was used to wash the cells to remove any minor amount of biochanin A. Consequently, A427 cells were cocultured with AML-193 cells in different ratios using low protein serum-free medium for $8 \mathrm{~h}$ at $37^{\circ} \mathrm{C}$. A427 cells cocultured with AML-193 and A427 cells cocultured with AML-193 in dimethyl sulfoxide served as the control and vehicle control, respectively. Conditioned medium was collected after $8 \mathrm{~h}$ of coculture and the dead cells were removed by centrifugation at 3,000 x $\mathrm{g}$ for $30 \mathrm{~min}$ and maintained at $-80^{\circ} \mathrm{C}$ for further use. Conditioned media with and without biochanin A treatment were represented as TCM and NTCM, respectively.

Quantification of cytokines. Supernatants of the culture media were used to quantify the amount of TNF- $\alpha$ (cat. no. 550610) and IL-6 (cat. no. 550799) levels using commercially purchased ELISA kits (BD Biosciences Franklin Lakes, NJ, USA) by following the instructions supplied by the manufacturer. Measurements were carried out in triplicate for all assays.

Wound healing assay. A427 cell lines were seeded in 6-well plates until 95\% confluency in DMEM. After removing the media, the cell monolayer was wounded using a sterile needle and was subsequently washed using PBS to remove the debris. Images were captured $(0 \mathrm{~h})$. Cell lines were subjected to treatment with both the treated and non-treated conditioned media (TCM and NTCM) and incubated for a further $24 \mathrm{~h}$. Images were captured after the wound formation $(24 \mathrm{~h})$. Three independent assays were performed and a percentage were calculated from wound closures with the help of a formula as previously outlined (30).

Invasion assay. Inserts of poly-carbonate filters (pore size, $8 \mathrm{~mm}$ ) were pre-polished using Matrigel and pre-incubated in DMEM for $\sim 3 \mathrm{~h}$ prior to plating the cells. The upper compartment was loaded with $250 \mathrm{ml}$ TCM/NTCM cocultured conditioned media of A427 cells at a density of $4 \times 10^{5}$, whereas the lower compartment was loaded with DMEM $(500 \mathrm{ml})$, which can function as a chemotactic element, and incubated 
for $24 \mathrm{~h}$. Following this, cotton buds were used to remove the non-migrated cells from the upper compartment and the migrated cells were then attached to the filter on the other side, fixed using formaldehyde (3.5\%) for $30 \mathrm{~min}$ and stained with crystal violet. Every five fields were calculated and quantified by recording absorbance at $570 \mathrm{~nm}$ for each elution of crystal violet using acetic acid (5\%). Data were represented as the mean of triplicate measurements.

Western blot analysis. Initially, the A427 pretreated cells were washed three times with ice-cold PBS solution. Cells were then lysed using radioimmunoprecipitation lysis buffer containing Tris-HCl (10 mM, pH 7.4), EDTA (1 mM), 1\% sodium deoxycholate, sodium chloride (100 mM) and NP-40 along with $1 \mathrm{X}$ Roche protease inhibitor composed of aprotinin and leupeptin (both $5 \mathrm{mg} / \mathrm{ml}$ ). Centrifugation was performed at $12,000 \mathrm{x} \mathrm{g}$ for $10 \mathrm{~min}$ at $4^{\circ} \mathrm{C}$ to obtain the cell lysates and protein concentrations were estimated using Bio-Rad Protein Assay reagent (Bio-Rad Laboratories, Inc., Hercules, CA, USA). Proteins were subsequently separated by SDS-PAGE and electrophoretically transferred onto polyvinylidene difluoride membranes followed by blocking with bovine serum albumin (1\%) for $\sim 3 \mathrm{~h}$ at room temperature. Membranes were subsequently incubated at $4^{\circ} \mathrm{C}$ overnight with primary antibodies against E-Cadherin, Snail and $\beta$-actin at dilution ratios of $1: 1,000,1: 1,000$ and 1:1,500, respectively. Blots obtained after washing were treated with infra-red (IRDye 800 CW Goat anti-Human IgG)-associated secondary antibodies (cat. no. 926-32232; LI-COR Biotechnology, Lincoln, NE, USA) at a dilution ratio of 1:10,000 for $\sim 2 \mathrm{~h}$ at room temperature. The resultant blots were scanned using a LAS 4000 Image Quant gel documentation system (GE Healthcare, Chicago, IL, USA).

Statistical analysis. One-way analysis of variance (ANOVA) was used for all statistical calculations. Tukey's honest significant difference was used as a post hoc test method following ANOVA. $\mathrm{P}<0.05$ was considered to indicate a statistically significant difference. All data were expressed as the mean \pm standard deviation of triplicate measurements.

\section{Results}

Determination of pro-inflammatory coculture requirements. To assess the potential of the pro-inflammatory co-culture method in simulating the original cancer micro-environment background, co-culture with different ratios $(1: 1,1: 10$, 1:15, 1:25 and 1:50) of A427 human lung cancer cell line with AML-193 human leukemic monocytic cell lines were performed for $\sim 6 \mathrm{~h}$. Once the cocultured conditioned medium was attained, we estimated the levels of cytokines (TNF- $\alpha$ and IL-6) using enzyme-associated immunoassays. Results of coculture indicated the formation of a significant amount of TNF- $\alpha$ and IL- 6 and the high response was monitored at a 1:15 cocultured ratio (Fig. 1). These types of cancer and myeloid cells (A427/AML-193) are generally identified only in solid tumors but not in liquid medium (31). In addition, generation of cytokines (TNF- $\alpha$ and IL-6) was not observed when using either A427 or AML-193 cultures alone. These results indicate the possible liberation of a stimulus from
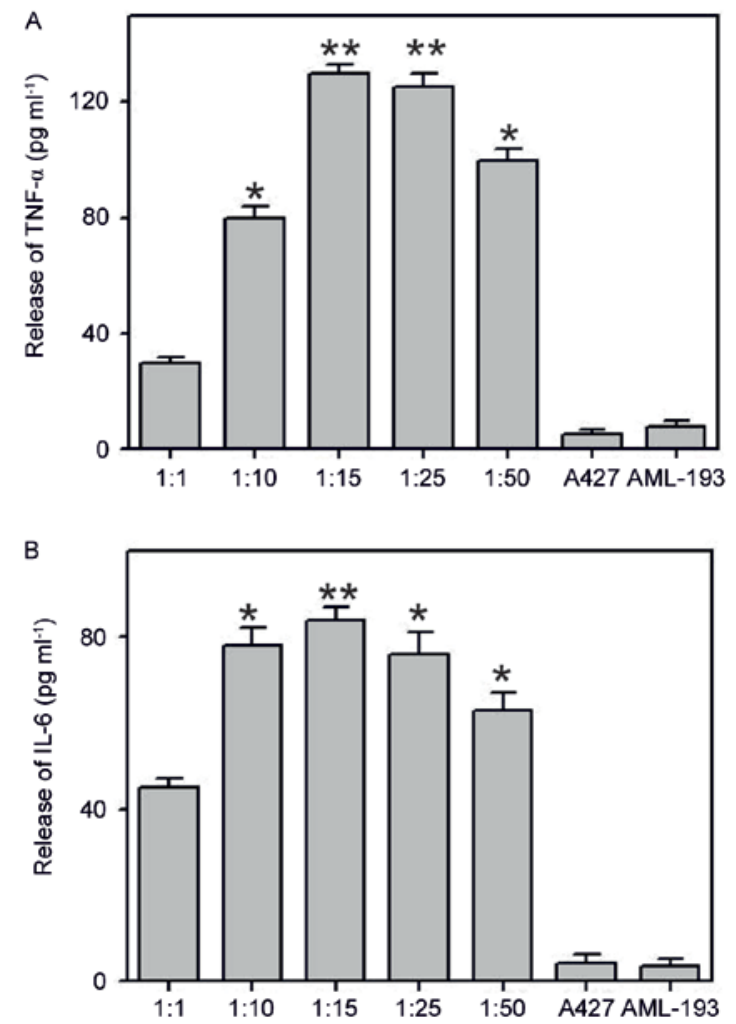

Figure 1. Pro-inflammatory milieu induced by coculturing of human lung cancer A427 cell line and human monocytic AML-193 cell line. A427 cells were cultured along with AML-193 at ratios of 1:1, 1:10, 1:15, 1:25 and 1:50. The 1:15 ratio produced a high inflammatory response. When cultured alone, neither of the cell lines were able to produce an inflammatory response for (A) TNF- $\alpha$ and (B) IL-6. Data are represented as mean + standard deviation. of three independent experiments. ${ }^{*} \mathrm{P}<0.05,{ }^{* *} \mathrm{P}<0.01$ vs. A427. TNF, tumor necrosis factor; IL, interleukin.

A427 cells that induces pro-inflammatory characteristics in AML-193 cells.

Assessment of sub-lethal dosages of biochanin A. In order to evaluate the role of biochanin A on cell viability and to examine the operative concentration that is able to produce negligible cytotoxicity to A427 cells, an MTT assay was conducted with sub-toxic dosages of biochanin A (5-40 $\mu \mathrm{M})$. Results of MTT demonstrated good cell viability, and thus no cytotoxicity, at all the measured dosages of biochanin A (Fig. 2).

Biochanin A inhibits the release of cancer cell generated pro-inflammatory markers from monocytic cells. In order to elucidate the effects of biochanin A on the pro-inflammatory response via a cocultured method, we performed pretreatment of A427 cells with biochanin A at sub-lethal concentrations of 5-40 $\mu \mathrm{M}$ for $\sim 24 \mathrm{~h}$ prior to coculture with AML-193 cells. Cytokine levels (TNF- $\alpha$ and IL-6) were quantified from the supernatant solutions of cell culture. Results demonstrated the significant suppression of TNF- $\alpha$ and IL- 6 liberation from AML-193 cells when compared to that of non-treated (control) or dimethyl sulfoxide treated cocultures (Fig. 3). It is known that pro-inflammatory cytokines have a crucial role in cancer metastasis (12) and the use of biochanin A results in the inhibition of the pro-inflammatory response from A427 cells, which might alter the cancer cell micro-environment. 


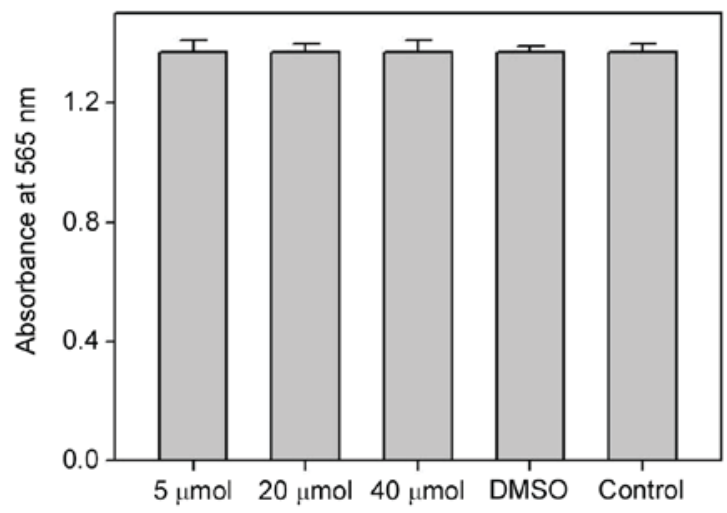

Figure 2. MTT assay was conducted to assess the cytotoxicity of A427 cells after treatment with 5-40 $\mu \mathrm{M}$ biochanin A for $24 \mathrm{~h}$. Data are represented as mean + standard deviation of three individual experiments.
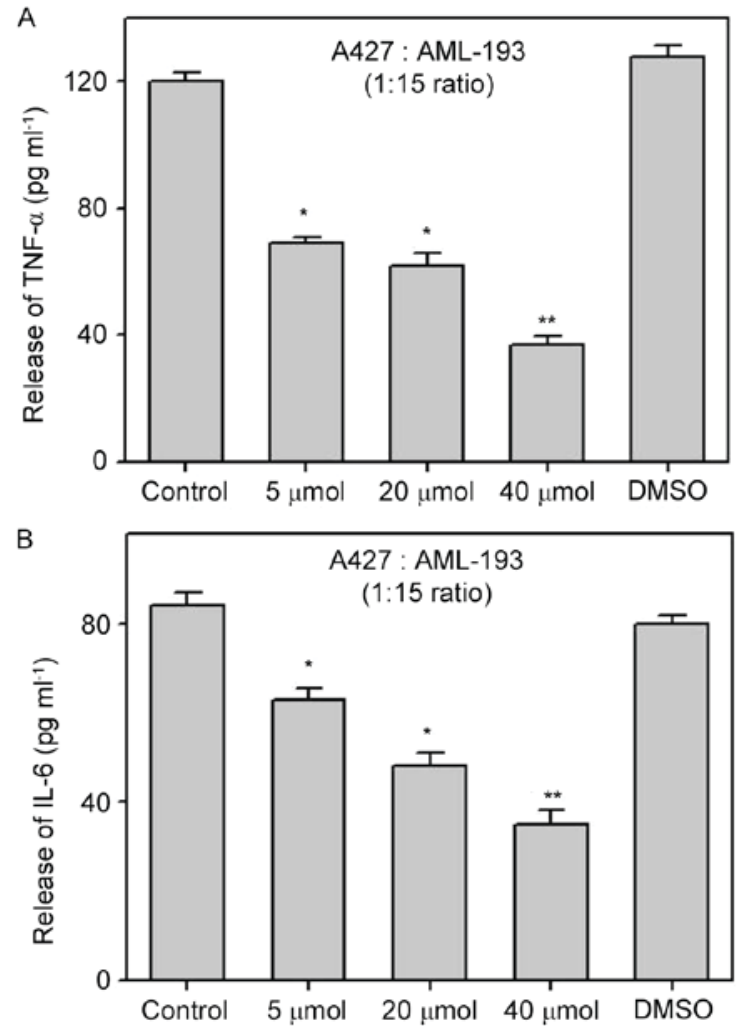

Figure 3. Release of pro-inflammatory mediators in AML-193 cells inhibited by biochanin A in coculture of A427 and AML-193 cell lines. Various concentrations of biochanin A were pretreated with A427 cell lines for $24 \mathrm{~h}$ and cocultured with AML-193 cells at a ratio of 1:15. Treatment of biochanin A resulted in concentration-based inhibition of TNF- $\alpha$ (A) and IL-6 (B) as compared with the blank control and DMSO controls. Data are represented as mean + standard deviation of three independent experiments ${ }^{*} \mathrm{P}<0.05 ;{ }^{* *} \mathrm{P}<0.01$ vs. Control. TNF, tumor necrosis factor; IL, interleukin.

Effect of biochanin A on the inhibition of migration and invasion in $A 427$ cells. Pro-inflammatory cytokines, such as TNF- $\alpha$ and IL-6, occurring in the cancer microenvironment governs the migration and invasive characteristics to the tumor cells (32). Since the results demonstrated that A427 induced AML-193 cells to produce TNF- $\alpha$ and IL- 6 cytokines, we examined whether biochanin A was able to alter the metastatic properties of A427 cells. Migration and invasion studies were

\section{A \\ Non-treated CM Biochanin A-treated CM}

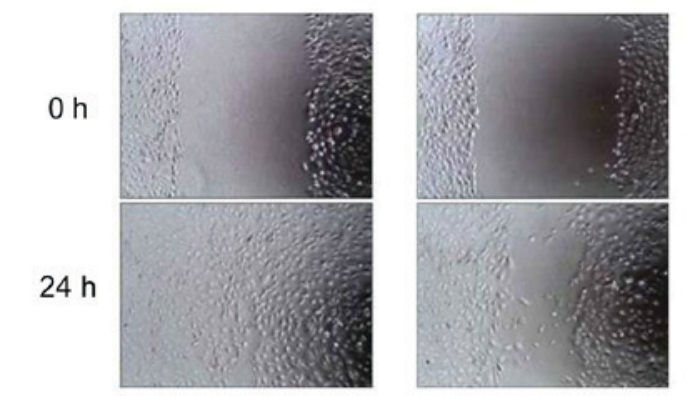

B

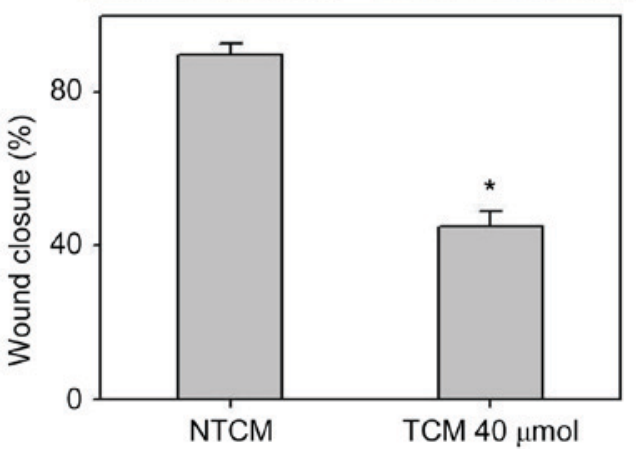

Figure 4. Effects of biochanin A on the migration of A427 cells imparted during coculture. Human lung cancer A427 cell lines were treated with or without $40 \mu \mathrm{M}$ of biochanin A for $24 \mathrm{~h}$ and cocultured with AML-193 cells at a ratio of 1:15 for $8 \mathrm{~h}$. CM was used for the healing of wounded monolayers of A427 cells for $48 \mathrm{~h}$. Drug treatment showed notable inhibition of wound healing, compared with the control. (A) Images demonstrate the initial wounds of A427 cells and after $48 \mathrm{~h}$ in the NTCM and TCM groups. (B) Quantification of three randomly selected scratched areas. Data are represented as mean + standard deviation of three individual experiments. "P<0.05 vs. NTCM. CM, conditioned medium; NTCM, non-treated conditioned medium; TCM, treated conditioned medium.

conducted with conditioned medium from biochanin $\mathrm{A}$ added cocultures of A427 and AML-193 cells. A427 cell lines were cultured to minimal confluency, wounded and further cultured in biochanin A-treated (TCM) or non-treated (NTCM) cocultured conditioned medium, respectively. The data revealed that biochanin A markedly reduced the transition of A427 cells as it reduced the wound healing process (Fig. 4). In addition to these results, A427 cells were cultured in NTCM or TCM (40 $\mu \mathrm{M}$ biochanin A) cocultured conditioned medium to further explore the effects using different in vitro cell line models. Data indicated that biochanin A strongly repressed the coculture-stimulated invasion of A427 cells (Fig. 5); a 19-fold reduction in the number of invasive cells was noted for TCM, as compared with that of NTCM.

Effect of biochanin A on E-cadherin and Snail expression via EMT. Strong correlations have been identified between EMT and pro-inflammatory cancer cell microenvironments $(33,34)$, which helps to activate cancer metastasis. It has previously been demonstrated that biochanin $\mathrm{A}$ is able to reduce pro-inflammatory activities and thereby hinder cancer metastasis (35); however, whether biochanin A can alter epithelial-mesenchymal transition still remains to be established. To analyze this, A427 cell lines were developed in non-treated or biochanin A-treated cocultured medium. A significant reduction in Snail expression and a simultaneous 


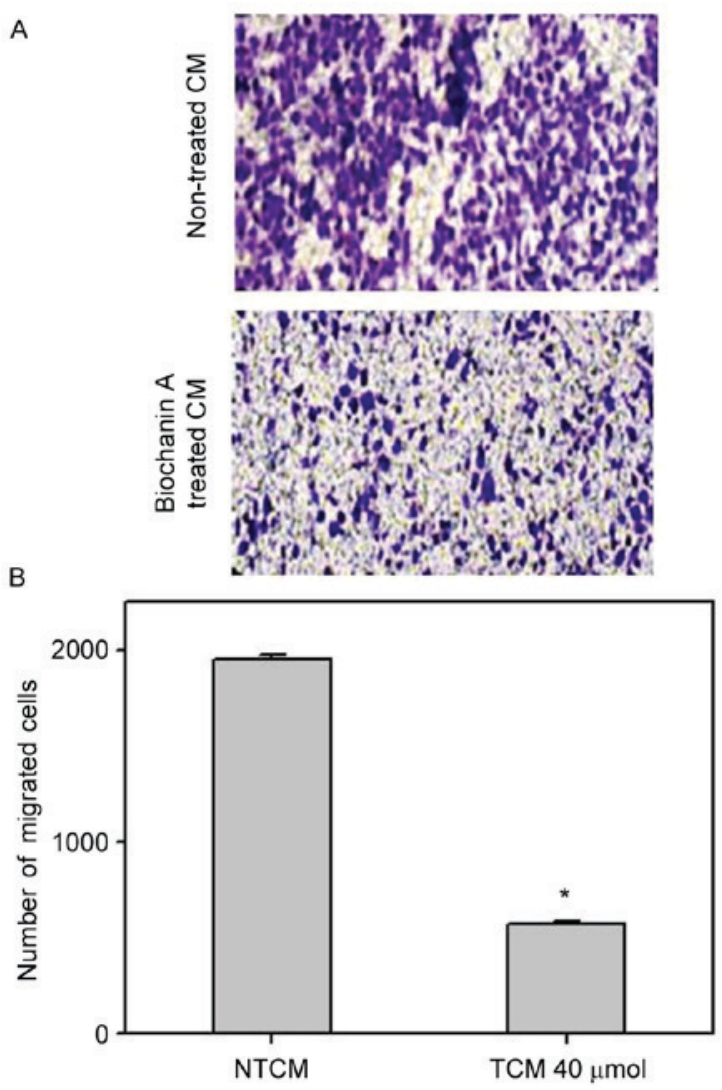

Figure 5. Invasiveness of A427 cells inhibited by biochanin A treatment. Human lung cancer A427 cell lines migrated through Transwell chambers coated with collagen for $24 \mathrm{~h}$ in the presence or absence of biochanin A. (A) Images of the cells were captured at a magnification of $\mathrm{x} 100$ after fixing and staining. (B) Quantification results of invasive cells from the microscopic observation. Data are represented as mean + standard deviation of three independent experiments. " $\mathrm{P}<0.05$ vs. NTCM. CM, conditioned medium; NTCM, non-treated conditioned medium; TCM, treated conditioned medium.

depression in E-cadherin was determined from western blot analysis data (Fig. 6), which is indicative of EMT as these are EMT bio-markers (32).

\section{Discussion}

There are numerous reports of successful induction of apoptosis in cancer cells using natural extracts derived from herbs $(36,37)$. Many of chemopreventive substances are currently used, but these kill both the normal and cancer cells with side effects. However, the usage of isolated natural compounds that are specific to cancer cells may decrease the side effects and indicate their use as successful therapeutic agents. It has been demonstrated that the inflammatory micro-environment has a crucial function in the metastatic development of several cancers (38). Numerous experimental studies and clinical trials, have clearly demonstrated that existence of tumor-infiltrating immune cells, particularly macrophages, which may promote cancer growth $(39,40)$. Certainly, tumor cells recruit macrophages and discharge elements that interact with cells in the cancer cavity to produce an inflammatory micro-environment. A number of studies have demonstrated the utility of anti-inflammatory substances in preventing tumors through anti-cancer treatments $(40,41)$.

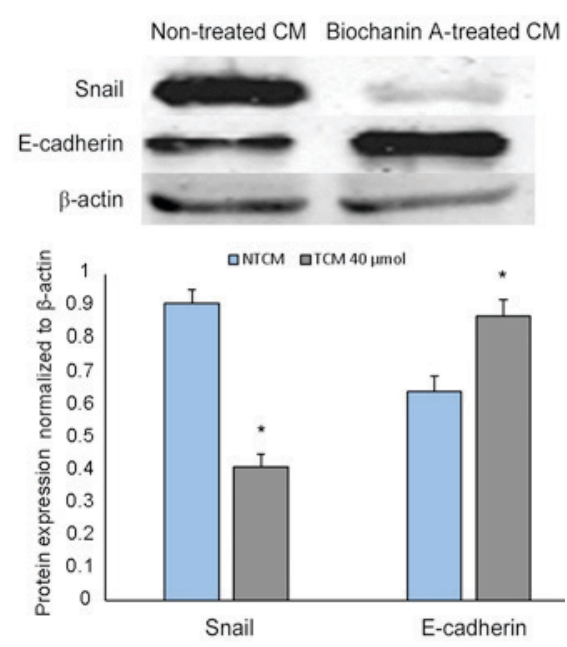

Figure 6. Coculture-induced epithelial-mesenchymal transition inhibited by biochanin A treatment in human lung cancer A427 cell lines. Cells were treated with or without biochanin A for $48 \mathrm{~h}$ and western blot analysis was performed to assess the expression of epithelial-mesenchymal transition markers, Snail and E-cadherin. "P<0.05 vs. NTCM. $\beta$-actin was used as an internal control.

The present study investigated the use of biochanin A as an anti-inflammatory drug to control the swelling stimulated by metastatic growth. We investigated, for the first time, whether the preparation of lung cancer cell lines with biochanin A prevents the potential of these tumor cells to induce leukemic monocytes apart from hindering coculture triggered liberation of TNF- $\alpha$ and IL- 6 cytokines at sub-lethal dosages in a concentration-dependent fashion. The findings demonstrated the hindering potential of biochanin A on the liberation of pro-inflammatory inducement from A427 lung cancer cell lines, which relates to the stimulation and consequent liberation of cytokines from AML-193 monocytes. Under the cancer micro-environment, it has been observed that cytokine release and other pro-inflammatory features result in the activation of cancer cells to perform EMT, thus advancing their migration and invasion $(42,43)$.

TNF- $\alpha$ has been suspected as driving functions that characterize the invasive nature of cancer by stimulating Snail sustainment, which is a prime transcription element that coordinated the cellular and molecular functions associated with EMT (42). In our case, we observed that A427 lung cancer cell lines cocultured with AML-193 leukemic monocytes resulted in the liberation of pro-inflammatory cytokines (TNF- $\alpha$ and IL-6) in the respective cultured medium. Conditioned medium accumulated from these AML-193 cells emphasized the transition potential of A427 cell lines, as determined by wound healing and migration assays. This was further demonstrated by the elevation of Snail expression with a simultaneous reduction in E-cadherin expression. However, biochanin A pre-treatment of A427 cells reduced activation and release of cytokines from AML-193 cells, as was mirrored by trace amounts of TNF- $\alpha$ and IL-6 in the cocultured condition medium. This was indicated by the reduced migration ability of A427 cells that received treatment with biochanin A, and altered E-cadherin and Snail protein expression.

In conclusion, data acquired from various experiments revealed that biochanin A hindered pro-inflammatory effects 
triggered from leukemic AML-193 monocytes in A427 human lung cancer cell lines. This characteristic of biochanin A was induced by the blockage of an inducing stimulus from A427 cells by a molecular mechanism that is still to be elucidated. Therefore, biochanin A was shown to possess strong inhibiting effects against cancer-evoked inflammation.

\section{Acknowledgements}

The authors would like to thank Hubei University of Medicine for their technical assistance.

\section{References}

1. Xu J, Liu X, Zhou S and Wei M: Combination of immunotherapy with anaerobic bacteria for immune gene therapy of solid tumours. Gene Ther Mol Biol 13: 36-52, 2009.

2. Bender E: Epidemiology: The dominant malignancy. Nature 513: S2-S3, 2014

3. Shibuya K, Mathers CD, Boschi-Pinto C, Lopez AD and Murray CJ: Global and regional estimates of cancer mortality and incidence by site: II. Results for the global burden of disease. BMC Cancer 2: 37, 2002.

4. Allemani C, Weir HK, Carreira H, Harewood R, Spika D, Wang XS, Bannon F, Ahn JV, Johnson CJ, Bonaventure A, et al: Global surveillance of cancer survival 1995-2009: Analysis of individual data for $25,676,887$ patients from 279 population-based registries in 67 countries (CONCORD-2). Lancet 385 977-1010, 2015.

5. Siegel RL, Miller KD and Jemal A: Cancer statistics, 2016. CA Cancer J Clin 66: 7-30, 2016.

6. Sharma SV, Bell DW, Settleman J and Haber DA: Epidermal growth factor receptor mutations in lung cancer. Nat Rev Cancer 7: 169-181, 2007.

7. Denlinger CE, Ikonomidis JS, Reed CE and Spinale FG: Epithelial to mesenchymal transition: The doorway to metastasis in human lung cancers. J Thorac Cardiovasc Surg 140: 505-513, 2010.

8. Thiery JP, Acloque H, Huang RY and Nieto MA: Epithelial-mesenchymal transitions in development and disease. Cell 139: 871-890, 2009.

9. Thiery JP and Sleeman JP: Complex networks orchestrate epithelial-mesenchymal transitions. Nat Rev Mol Cell Biol 7: 131-142, 2006.

10. Batlle E, Sancho E, Franci C, Dominguez D, Monfar M, Baulida J and García De Herreros A: The transcription factor snail is a repressor of E-cadherin gene expression in epithelial tumour cells. Nat Cell Biol 2: 84-89, 2000.

11. Cano A, Perez-Moreno MA, Rodrigo I, Locascio A, Blanco MJ, del Barrio MG, Portillo F and Nieto MA: The transcription factor snail controls epithelial-mesenchymal transitions by repressing E-cadherin expression. Nat Cell Biol 2: 76-83, 2000.

12. Casas E, Kim J, Bendesky A, Ohno-Machado L, Wolfe CJ and Yang J: Snail2 is an essential mediator of Twist1-induced epithelial mesenchymal transition and metastasis. Cancer Res 71: 245-254, 2011.

13. Graham RE, Gandhi TK, Borus J, Seger AC, Burdick E, Bates DW, Phillips RS and Weingart SN: Risk of concurrent use of prescription drugs with herbal and dietary supplements in ambulatory care. In: Advances in Patient Safety: New Directions and Alternative Approaches, Vol. 4. Henriksen K, Battles JB, Keyes MA., Grady ML. (eds). Agency for Healthcare Research and Quality (US), Rockville, MD, pp1-22, 2008.

14. Peng CC, Glassman PA, Trilli LE, Hayes-Hunter J and Good CB: Incidence and severity of potential drug-dietary supplement interactions in primary care patients: An exploratory study of 2 outpatient practices. Arch Intern Med 164: 630-636, 2004.

15. Rhee SM, Garg VK and Hershey CO: Use of complementary and alternative medicines by ambulatory patients. Arch Intern Med 164: 1004-1009, 2004

16. Dergal JM, Gold JL, Laxer DA, Lee MS, Binns MA, Lanctôt KL, Freedman M and Rochon PA: Potential interactions between herbal medicines and conventional drug therapies used by older adults attending a memory clinic. Drugs Aging 19: 879-886, 2002.
17. Breinholt V, Hossaini A, Svendsen GW, Brouwer C and Nielsen E: Estrogenic activity of flavonoids in mice. The importance of estrogen receptor distribution, metabolism and bioavailability. Food Chem Toxicol 38: 555-564, 2000.

18. Wang QY, Meng QH, Zhang ZT, Tian ZJ and Liu H: Synthesis solubility lipids-lowering and liver-protection activities of sulfonated formononetin. Yao Xue Xue Bao 44: 386-389, 2009 (In Chinese).

19. Kole L, Giri B, Manna SK, Pal B and Ghosh S: Biochanin-A, an isoflavon, showed antiproliferative and anti-inflammatory activities through the inhibition of iNOS expression, p38-MAPK and ATF-2 phosphorylation and blocking NF $\kappa$ B nuclear translocation. Eur J Pharmacol 653: 8-15, 2011.

20. Michaelis M, Sithisarn P and Cinatl J Jr: Effects of flavonoid-induced oxidative stress on anti-H5N1 influenza a virus activity exerted by baicalein and biochanin A. BMC Res Notes 7: 384, 2014.

21. Qiu L, Lin B, Lin Z, Lin YP, Lin M and Yang X: Biochanin A ameliorates the cytokine secretion profile of lipopolysaccharide-stimulated macrophages by a PPAR $\gamma$-dependent pathway. Mol Med Rep 5: 217-222, 2012.

22. Chen HQ, Jin ZY and Li GH: Biochanin A protects dopaminergic neurons against lipopolysaccharide-induced damage through inhibition of microglia activation and proinflammatory factors generation. Neurosci Lett 417: 112-117, 2007.

23. Biradar SM, Joshi $\mathrm{H}$ and Chheda TK: Biochanin-A ameliorates behavioural and neurochemical derangements in cognitive-deficit mice for the betterment of Alzheimer's disease. Hum Exp Toxicol 33: 369-382, 2014.

24. Mishra P, Kale RK and Kar A: Chemoprevention of mammary tumorigenesis and chemomodulation of the antioxidative enzymes and peroxidative damage in prepubertal Sprague Dawley rats by Biochanin A. Mol Cell Biochem 312: $1-9,2008$.

25. Zhang S and Morris ME: Effect of the flavonoids biochanin $\mathrm{A}$ and silymarin on the P-glycoprotein-mediated transport of digoxin and vinblastine in human intestinal Caco-2 cells. Pharm Res 20: 1184-1191, 2003.

26. Harini R, Ezhumalai M and Pugalendi KV: Antihyperglycemic effect of biochanin A, a soy isoflavone, on streptozotocin-diabetic rats. Eur J Pharmacol 676: 89-94, 2012.

27. Ko WC, Lin LH, Shen HY, Lai CY, Chen CM and Shih CH: Biochanin A, a phytoestrogenic isoflavone with selective inhibition of phosphodiesterase 4, suppresses ovalbumininduced airway hyperresponsiveness. Evid Based Complement Alternat Med 2011: 635058, 2011.

28. Tan JW, Tham CL, Israf DA, Lee SH and Kim MK: Neuroprotective effects of biochanin A against glutamate-induced cytotoxicity in PC12 cells via apoptosis inhibition. Neurochem Res 38: 512-518, 2013

29. Breikaa RM, Algandaby MM, El-Demerdash E and Abdel-Naim AB: Multimechanistic antifibrotic effect of biochanin a in rats: Implications of proinflammatory and profibrogenic mediators. PLoS One 8: e69276, 2013.

30. Rah B, Amin H, Yousuf K, Khan S, Jamwal G, Mukherjee D and Goswami A: A novel MMP-2 inhibitor 3-azidowithaferin A (3-azidoWA) abrogates cancer cell invasion and angiogenesis by modulating extracellular par-4. PLoS One 7: e44039, 2012.

31. Jiménez-Orozco FA, López-González JS, Nieto-Rodriguez A, Velasco-Velázquez MA, Molina-Guarneros JA, Mendoza-Patiño N, García-Mondragón MJ, Elizalde-Galvan P, León-Cedeño F and Mandoki JJ: Decrease of cyclin D1 in the human lung adenocarcinoma cell line A-427 by 7-hydroxycoumarin. Lung Cancer 34: 185-894, 2001

32. Wu Y, Deng J, Rychahou PG, Qiu S, Evers BM and Zhou BP: Stabilization of Snail by NF-kappaB is required for inflammation-induced cell migration and invasion. Cancer Cell 15: 416-428, 2009.

33. DeNardo DG, Andreu P and Coussens LM: Interactions between lymphocytes and myeloid cells regulate pro-versus anti-tumor immunity. Cancer Metastasis Rev 29: 309-316, 2010.

34. Qian BZ and Pollard JW: Macrophage diversity enhances tumor progression and metastasis. Cell 141: 39-51, 2010.

35. Breikaa RM, Algandaby MM, El-Demerdash E and Abdel-Naim AB: Multimechanistic antifibrotic effect of biochanin A in rats: Implications of proinflammatory and profibrogenic mediators. PLoS One 16: e69276, 2013. 
36. Banjerdpongchai R, Khawon $\mathrm{P}$ and Pompimon W: Phytochemicals from Goniothalamus griffithii Induce Human Cancer Cell Apoptosis. Asian Pac J Cancer Prev 17: 3281-3287, 2016.

37. Shyur LF, Chen CH, Lo CP, Wang SY, Kang PL, Sun SJ, Chang CA, Tzeng CM and Yang NS: Induction of apoptosis in MCF-7 human breast cancer cells by phytochemicals from Anoectochilus formosanus. J Biomed Sci 11: 928-939, 2004.

38. Mantovani A, Allavena P, Sica A and Balkwill F: Cancer-related inflammation. Nature 454: 436-444, 2008.

39. Torisu H, Ono M, Kiryu H, Furue M, Ohmoto Y, Nakayama J, Nishioka Y, Sone S and Kuwano M: Macrophage infiltration correlates with tumor stage and angiogenesis in human malignant melanoma: Possible involvement of TNFa and IL-1alpha. Int J Cancer 85: 182-188, 2000.
40. Rayburn ER, Scharri SJ and Zhang R: Anti-inflammatory agents for cancer therapy. Mol Cell Pharmacol 1: 29-43, 2009.

41. Ricchi P, Zarrilli R, Di Palma A and Acquaviva AM: Anti-inflammatory drugs in colorectal cancer: From prevention to therapy. Br J Cancer 88: 803-807, 2003.

42. Thiery JP: Epithelial-mesenchymal transitions in tumour progression. Nat Rev Cancer 2: 442-454, 2002.

43. Wu Y, Deng J, Rychahou PG, Qiu S, Evers BM and Zhou BP Stabilization of Snail by NF-kappaB is required for inflammation-induced cell migration and invasion. Cancer Cell 15 416-428, 2009.

(i) $(-)$ This work is licensed under a Creative Commons Attribution-NonCommercial-NoDerivatives 4.0 International (CC BY-NC-ND 4.0) License. 